\section{REGIONAL CONSERVATION}

\section{The Conservation Atlas of Tropical Forests: Africa edited by Jeffrey A. Sayer, Caroline S. Harcourt and N. Mark Collins (Macmillan for IUCN, 1992, ISBN 0333 57757 4, 288 pp., HB £75)}

This atlas is the second (the first focused on Asia and the Pacific) in a series planned to cover tropical rain forest throughout the world. In the Foreword, Martin Holdgate, Director General of IUCN - The World Conservation Union, says that is aimed at all concerned with conservation and sustainable living in the forested zone of Africa, particularly the emerging generation of African conservationists.

The book is divided into two parts. The first contains 10 overview chapters covering history of the forests and climate, biological diversity, case studies in conserving large mammals, forest people, the effects of human population pressures, the timber trade, forest management, protected areas and the future.

Part II has chapters devoted to individual countries or groups of countries within the scope of the Atlas's coverage, which is closed canopy moist forest between the Tropics of Cancer and Capricorn, from Ethiopia in the north-east and Senegal in the north-west to Mozambique, Zimbabwe and Angola in the south as well as the islands of Madagascar, Seychelles, Comoros, Mauritius and Réunion.

The country accounts each include a map or a series of maps at the scale of 1:3 million or 1:4 million, showing the known extent of the forests and the distribution of protected areas. The accompanying text follows a standard format for each country, with a preliminary overview, a detailed account of the forests and their management, deforestation, biodiversity, conservation areas and a description of existing conservation initiatives. The text is enlivened with tables, coloured photographs of forests and wildlife and boxes containing summaries of important conservation projects.

The overall impression is of a great wealth of knowledge contributed by hundreds of specialists and compressed into a relatively small space. There are extensive references for those wishing for more information. The spatial data recorded in the book are stored in digital form at the World Conservation Monitoring Centre, Cambridge, UK and the Centre will be pleased to collaborate with organizations wishing to apply the data in the interest of nature conservation.

For a reference source the index could have been more comprehensive: for example, searching for reference to the Bwindi Forest (where it is mentioned in passing) one is directed to page 20 , and from there to Chapter 31 (no page nos.) where Bwindi is treated in depth (p. 266). The index gave no reference for the roloway monkey (p. 40), although one could track it down to the previous page where it was referred to only as the eastern subspecies of the Diana monkey Cercopithecus diana roloway. It is a pity that the chapter on conserving large mammals dealt only with elephants and primates (and why no mention of the African elephant's listing on Appendix I of CITES when urging that the ivory trade be controlled or shut down?).

Such quibbles aside the book is an immensely valuable con- tribution to promoting the conservation of Africa's threatened forests and I hope that its high price does not prevent it reaching those who need it most.

Editor

\section{Wild Indonesia: The Wildlife and Scenery of the Indonesian Archipelago by Tony and Jane Whitten, photographs by Gerald Cubitt (New Holland, London, in association with World Wide Fund for Nature, 1992, ISBN 1853681288,208 pp., HB £24.99)}

Embracing some 13,000 islands spread over nearly 4000 equatorial kilometres, covering an area of nearly 2 million sq $\mathrm{km}$ and containing 180 million people (with 60 per cent living in 7 per cent of the nation's land area: Java), Indonesia offers a unique spectrum of scenery, habitats and wildlife a photographer's paradise. Indeed, everyone should be able to find their corner of paradise there. Along with Brazil and Zaire, Indonesia has been coined a 'megadiversity country' (by American conservationists of course!) because of the diversity of habitats and wildlife.

These three countries contain more than 50 per cent of the planet's tropical rain forests, but Indonesia bridges two continents - Asia and Australasia and in spanning Wallace's Line, it contains the intriguing mixture of Asian continental wildlife (elephants, tigers, rhinoceroses, monkeys and apes) and Australian marsupials, with an amazing spectrum of invertebrates, fishes, amphibians, reptiles, birds and mammals. And all this in dramatic volcanic scenery, spanning the length of the country, and in the most complex evergreen forest vegetation in the 